\title{
SOCKET DESIGN AND CEMENT PRESSURISATION IN THE CHARNLEY LOW-FRICTION ARTHROPLASTY
}

\author{
P. SHELLEY, B. M. WROBLEWSKI \\ From the Centre for Hip Surgery, Wrightington
}

\begin{abstract}
An experimental evaluation was made of the efficacy of an unflanged cup, an ogee-flanged cup and the Exeter pressuriser in the pressurisation of acetabular cement. Only a very modest injection pressure could be generated through an unflanged socket and even this was readily lost as the socket "bottomed out". The ogeeflanged socket gave a consistently high injection pressure which could be maintained throughout the process of polymerisation. The Exeter pressuriser gave marginally better results. Of the two cements tested, Palacos with gentamicin showed better intrusion than CMW Type 1 cement, but it also allowed greater extrusion once pressure was released. The importance of maintaining a continuous pressure on the cement throughout polymerisation is emphasised.
\end{abstract}

There is little doubt that the main long-term problem with the Charnley low-friction arthroplasty is likely to be loosening of the socket. Such loosening is related to wear of the socket (Wroblewski 1985 a and b, 1986) which is inevitable, but loosening is also affected by the design of the socket and the method of its insertion - both of which have changed over a number of years.

High density polyethylene (HDP) was first used for sockets in November 1962. The design of the cup evolved in a series of stages (Fig. 1). Initially it was rimless, then anchoring grooves were improved and scallops were added in order to locate the socket holder, centre the socket within the acetabulum, and increase the torsional resistance of the socket within the cement. In 1976 the pressure-injection flanged socket was introduced. The plastic flange could be trimmed to seal round the acetabular rim and improve the pressurisation of the cement.

The original symmetrical flange made it difficult to avoid placing the socket in anteversion, but the successive use of HDP, high molecular weight polyethylene (HMWP) and the ultra-high molecular weight polyethylene (UHMWP) restricted the socket design to a shape that was symmetrical and could therefore be readily machined from a solid block.

In 1981 cross-linked polyethylene (XLPE) was introduced. This material could be injection-moulded into any shape and then cross-linked. The availability of

P. Shelley, PhD, Research Fellow

B. M. Wroblewski, FRCS, Consultant Orthopaedic Surgeon

Centre for Hip Surgery, Wrightington Hospital, Wigan, Lancashire WN6 9EP, England.

Correspondence should be sent to Dr P. Shelley.

(C) 1988 British Editorial Society of Bone and Joint Surgery $0301-620 \mathrm{X} / 88 / 3069 \$ 2.00$

J Bone Joint Surg [Br] 1988;70-B:358-63.
XLPE allowed Charnley to design the ogee-flanged socket (ogee is an architectural term for a change in the direction of a curved plane). The new design took into account the asymmetry of the acetabular margins, maximised the area of contact between bone and cement, and maintained the neutral orientation of the socket.

The purpose of this study is to evaluate the ogeeflanged socket in terms of its efficacy in pressurising the acetabular cement and to compare it with the scallopededge socket and the custom-designed Exeter pressuriser. Two types of acrylic cement were used: CMW Type 1 and Palacos with gentamicin.

\section{EXPERIMENTAL METHOD}

The apparatus constructed for this study is shown schematically in Fig. 2. It comprises an "acetabulumshaped" cavity from the centre of which a $5 \mathrm{~mm}$ diameter orifice leads to a tube-type rheometer. The size of this orifice was chosen as typical of the size of the multiple drill holes made at operation to prepare the acetabulum. Its mouth could be occluded by fine metal gauze with a pore size similar to that of dense cancellous bone. Above the "acetabular cavity" a mechanism allowed the different designs of sockets to be pushed into the cement-filled cavity with a given force whilst maintaining socket alignment.

The rheometer tube was filled with liquid paraffin, and connected to a calibrated mercury column and to a piston arrangement which could maintain a constant back-pressure. When a flanged socket was tested the flange was trimmed manually to fit snugly inside the rim of the acetabular mould, but small leaks were tolerated.

An $8 \mathrm{~kg}$ load was chosen for most of the tests. This load was selected because it is typical of that which can be comfortably maintained in clinical practice for the extended period of cement polymerisation. Higher loads 
can of course be applied for short periods; the effect of this is described later. Five sets of experiments were carried out, each being repeated three times with each of the two cements and recorded as a mean value.

Pressures generated. Our initial tests measured the cement pressures created by the various devices. The socket or the pressuriser was pushed into the cement, starting two minutes after mixing had begun and, using a continuous force of $8 \mathrm{~kg}$, the pressure generated was measured by noting the height to which the paraffin elevated the mercury column; it was recorded every 15 seconds.

Cement intrusion into anchor holes. We then tested the extent of cement intrusion into the rheometer tube for the different devices. In all intrusion tests a constant backpressure of $25 \mathrm{mmHg}$ was used to simulate the blood pressure within the bone. Cement was mixed at $20^{\circ} \mathrm{C}$ for one minute and then poured into the acetabular cavity. Two minutes after mixing had started, a downward insertion force was applied to the socket or pressuriser. As cement was forced into the rheometer tube, liquid paraffin was drawn off in order to maintain the constant consistent model was justified because of the comparative nature of the study.

Abrupt pressure interruption. This was tested by experiments in which the $8 \mathrm{~kg}$ insertion load was abruptly removed after varying periods of pressurisation; this technique is frequently used in clinical practice.

Abrupt cessation of high insertion pressure. A final series of experiments was carried out using a higher insertion force of $20 \mathrm{~kg}$ for short periods, followed by a complete and abrupt removal of load. This technique also is used clinically in the belief that the initial penetration of cement, once achieved, remains unaltered during polymerisation.

\section{RESULTS}

Cement pressure. Theoretically, the maximum pressure generated by an acetabulum of $50 \mathrm{~mm}$ diameter used with an insertion force of $8 \mathrm{~kg}$ is $300 \mathrm{mmHg}$. In no test did the pressure reach this value, but this reflects the fact that the pressure was being measured at a point some distance down the rheometer tube. The method is,

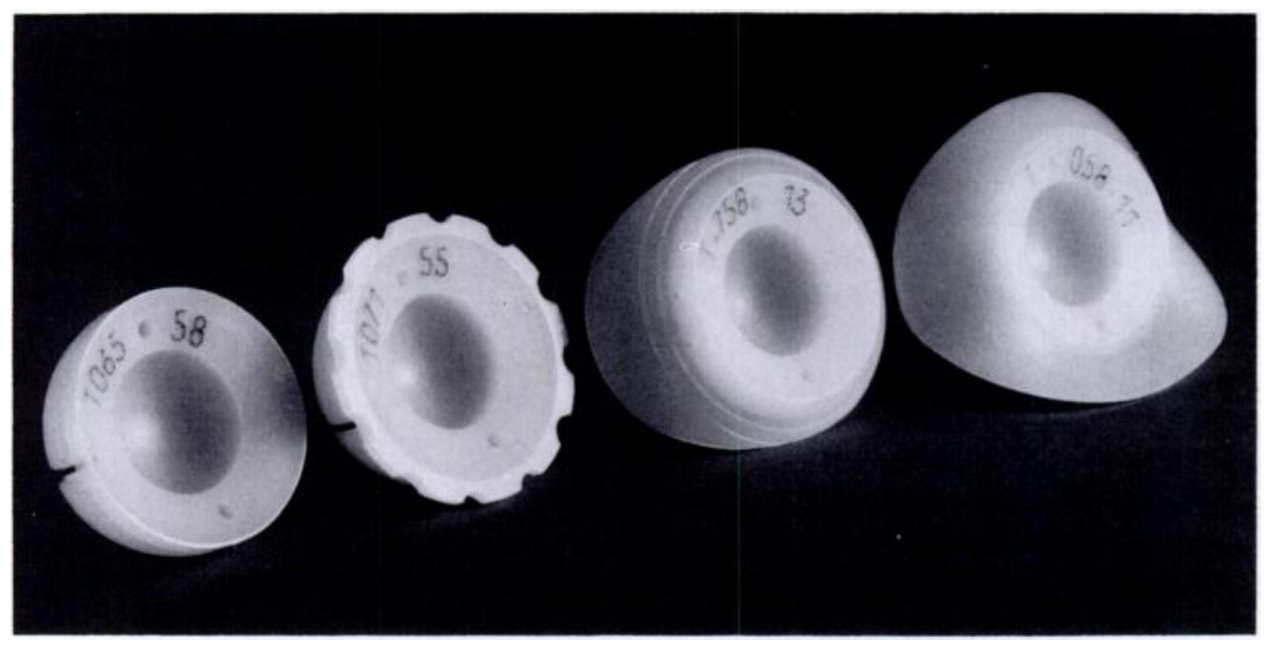

Fig. 1

Evolution of the Charnley socket from the rimless type to the ogee-flanged model.

back-pressure. Each time the intrusion volume was to be measured (usually every 30 seconds), liquid paraffin was returned to the rheometer tube and the height of the mercury column was recorded. This method of measurement does, for 3 to 4 seconds, involve the application of a slightly larger back-pressure than $25 \mathrm{mmHg}$, but we felt that this would not have a significant effect on the test results, especially as this was a comparative study, and all results would be similarly affected.

Cement intrusion into simulated cancellous bone. We then determined cement intrusion when the mouth of the rheometer was occluded with metal gauze. A pore size of $600 \mu \mathrm{m}$ was chosen as representative of the pore size in dense cancellous bone. Again, the use of a simple but

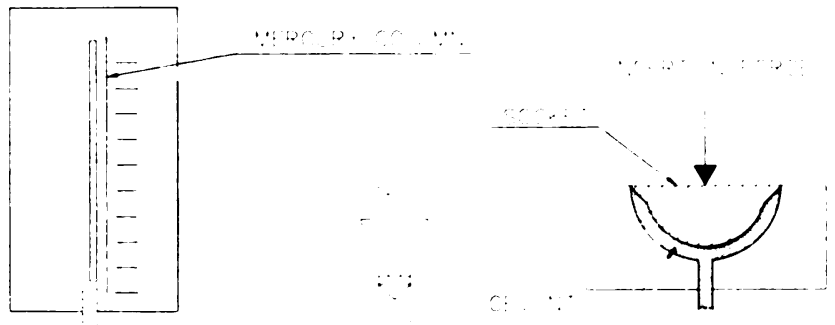

Fig. 2 
however, valid because it is the effective pressure at the interface between cancellous bone and cement which produces intrusion. The cement pressure within the acetabulum itself is of less interest, although it would almost certainly be near the theoretical maximum when a flanged socket or a pressuriser is used.

An unflanged socket with an insertion force of $8 \mathrm{~kg}$ produced a peak pressure of $46 \mathrm{mmHg}$ with $\mathrm{CMW}$ cement and $42 \mathrm{mmHg}$ with Palacos with gentamicin. A flanged socket produced peak pressures of $170 \mathrm{mmHg}$, with CMW Type 1 and $185 \mathrm{mmHg}$ with Palacos, while the Exeter pressuriser, tested with Palacos cement, gave a mean peak pressure of $193 \mathrm{mmHg}$.

Intrusion into $5 \mathrm{~mm}$ holes. The results for the series of cement intrusion tests are shown in Figure 3 as a plot of the volume of cement intruded versus time.

Unflanged sockets. The curves for unflanged sockets flatten out after one minute and then have a negative slope. The peak of these curves is at the moment at which the socket "bottoms out" within the acetabulum, making further pressurisation impossible. The curves then descend quickly because the $25 \mathrm{mmHg}$ back-pressure is effective against the still liquid cement and starts to expel some intruded cement from the rheometer tube. As the cement polymerises, its viscosity rises and the rate of extrusion decreases, but by 4.5 minutes the volume of cement intruded is reduced to that obtained before force was applied to the socket. By the time the cement had set, 7 minutes from insertion, there had been a net extrusion of cement.

The two cements behaved differently. Palacos had a slightly greater tendency both to intrude into the drill hole, and also to leak around the periphery of the unflanged socket. Therefore the socket "bottomed out" more readily with Palacos, but with comparable intrusion. Because Palacos polymerises more slowly than CMW Type 1, there is a longer period during which back-pressure can expel the cement, so the net extrusion of cement was greater in the tests using Palacos.

In all the drill hole tests, liquid paraffin forced a path between the cement and the apparatus during the phase of extrusion of cement. We consider that this effect is similar to that seen to be produced by blood in the clinical situation.

Flanged sockets. The results of using the ogee-flanged socket with the two types of cement are also shown in Figure 3. There is an immediate and marked contrast in the intrusion curves, with a greater initial gradient, a much higher intruded volume and then a gradual reduction in the intrusion rate with time. Again there is a difference between the two cements, Palacos showing a more fluid response and consequently a greater intruded volume.

Exeter pressuriser. The intrusion curves for the Exeter acetabular cement pressuriser used with both cement types are compared with one curve for a flanged socket in Figure 4. The Exeter pressuriser gave a slightly higher intruded volume than the flanged socket by an average of $6 \%$. This difference is almost certainly a reflection of the more pliable nature of the pressuriser as compared to the material of the flange. Although "rimming out" of the flange was meticulously avoided, it is clear that friction on the sides of the acetabular cavity could have contributed to the effect.

Intrusion through small pores. The results for intrusion of cement through $600 \mu \mathrm{m}$ gauze are shown in Figure 5 with one curve from a drill hole test for comparison.

Unflanged socket. The plot for an unflanged socket demonstrates that very little cement is intruded before the socket "bottoms out" as a result of peripheral leakage of the cement.

Flanged socket. With a flanged socket the initial intrusion rate is lower in the gauze test and there is a considerable reduction of intruded volume. At the time of polymerisation this was only $18 \%$ of that achieved in the drill hole test. Palacos cement again showed a higher intrusion volume than CMW Type 1 .

Abrupt pressure interruption. The results of using a short duration of $8 \mathrm{~kg}$ insertion force are shown in Figure 6.

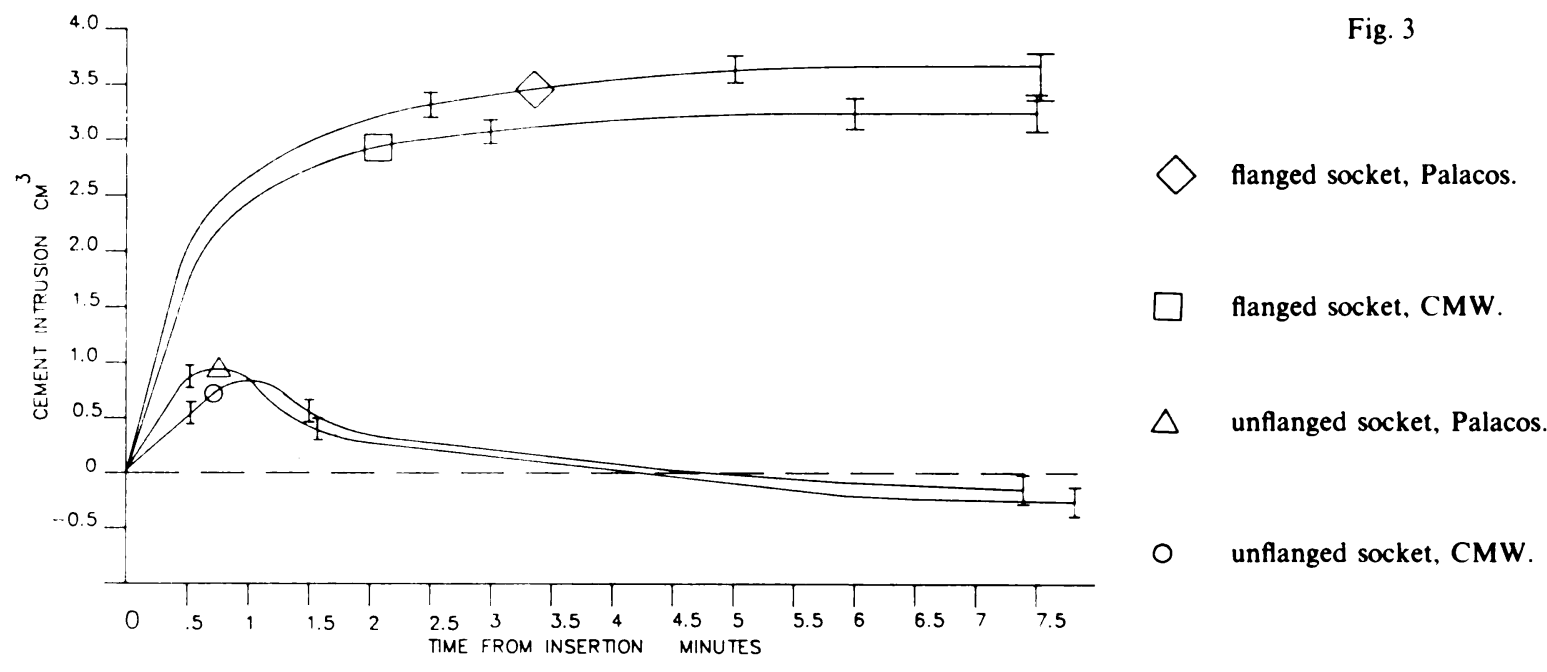




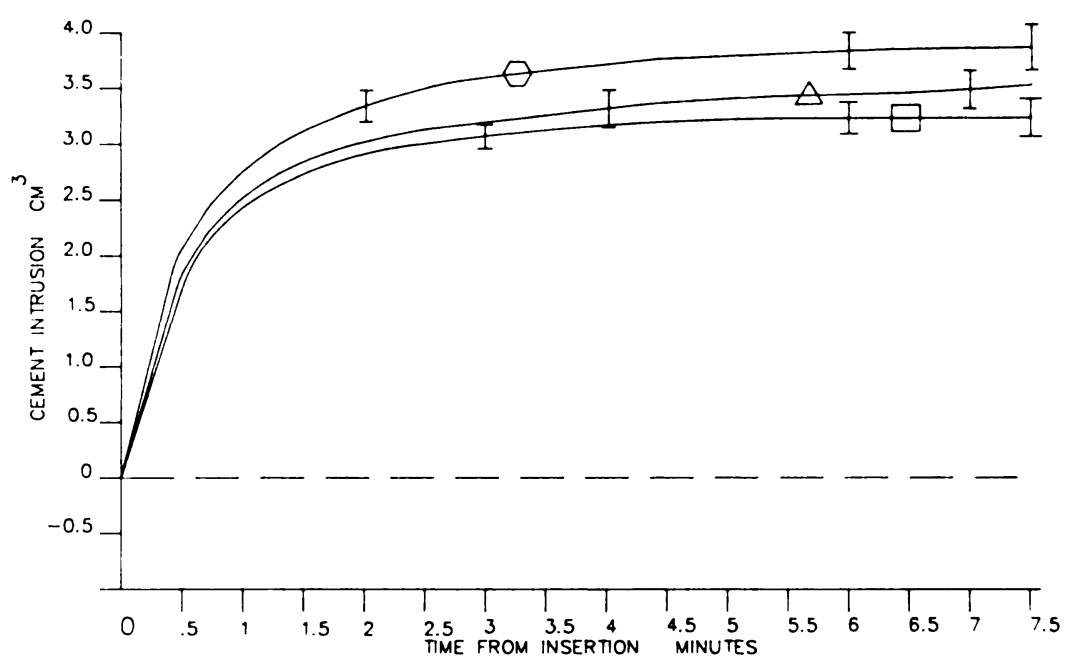

Fig. 4

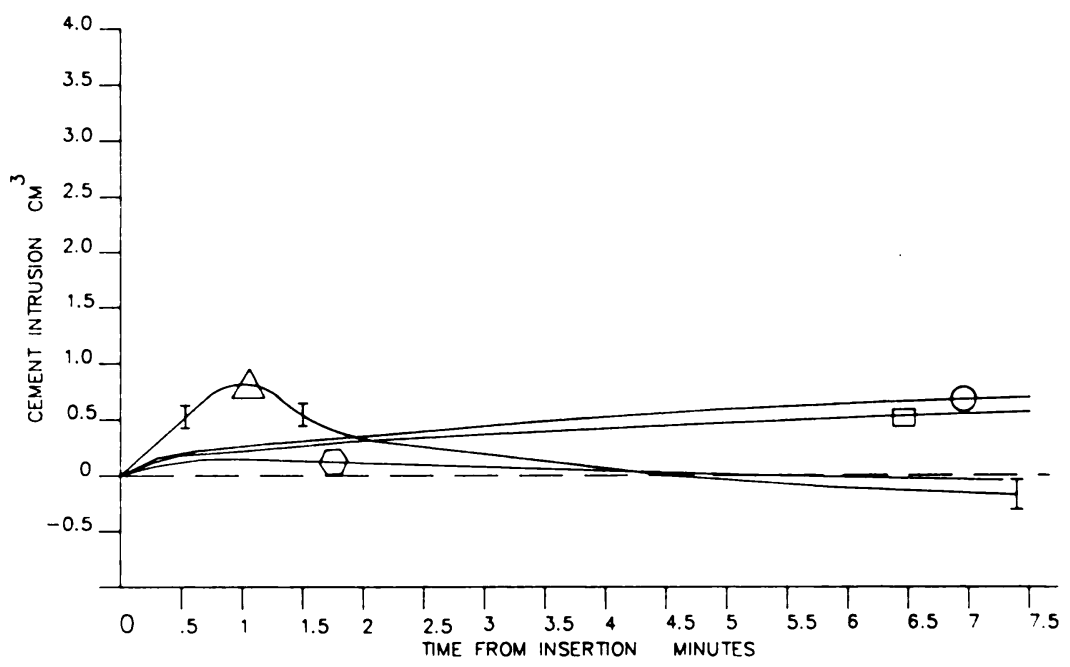

$\triangle$ Exeter pressuriser, CMW.

Exeter pressuriser, Palacos.

\section{flanged socket, CMW.}

flanged socket, gauze, Palacos.

$\square$ flanged socket, gauze, CMW.

0 unflanged socket, gauze, CMW.

$\triangle$ unflanged socket, no gauze, CMW.

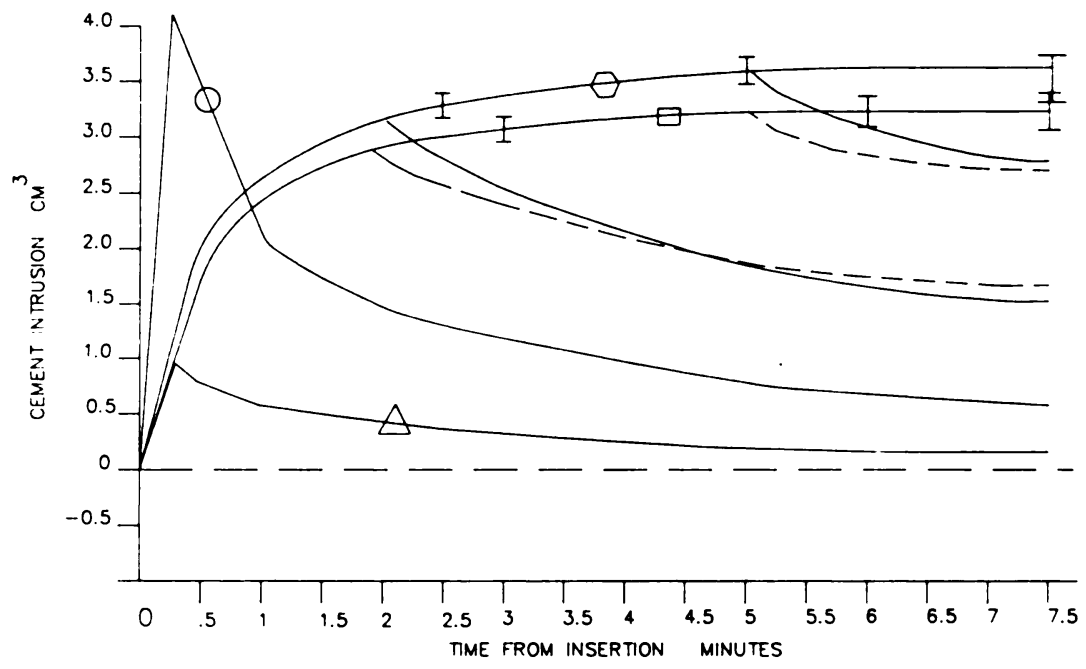

Fig. 6

flanged socket, $\mathrm{CMW}, 20 \mathrm{~kg}$ for 15 seconds.

$\square$ flanged socket, CMW, load removed at 2 and 5 minutes.

flanged socket, Palacos, load removed at 2 and 5 minutes.

$\triangle$ flanged socket, gauze, CMW, $20 \mathrm{~kg}$ for 15 seconds.

Figures 3 to 6 show the volume of cement intruded plotted against time under pressure for various combinations of socket or pressuriser and cement (see text). 
The insertion force was abruptly removed at various time intervals during polymerisation, and the effect of this is seen to be similar to that of "bottoming out" in the earlier tests with unflanged sockets: extrusion of cement starts as soon as the load is removed, but the rate of extrusion slows down as the cement polymerises.

Abrupt cessation of high insertion pressure. An insertion force of $20 \mathrm{~kg}$ was used for 15 seconds; the results are shown in Figure 6. When a flanged socket was used in this way without gauze, a large volume of cement was intruded, but was largely expelled again after cessation of force. The same test with the gauze in place showed considerable intrusion but this was less than that obtained by using a smaller force for a longer period. Once again a large proportion of the cement was extruded after cessation of the insertion force.

\section{DISCUSSION}

The fact that improved fixation for the socket is needed is not in dispute. Long-term results show increasing rates of socket loosening, but there may be reasons other than poor initial fixation (Wroblewski 1986). It has been shown by Lee (1983) that an intramedullary bleeding pressure of only $27 \mathrm{~mm} \mathrm{Hg}$ is enough to force blood between bone and cement. This pressure must be overcome by a substantial margin if cement intrusion is to be facilitated.

Several methods of improving cement injection into acetabular bone have been investigated. Lee and Ling (1974) developed the balloon-type acetabular cement pressuriser which was tested in our study; they reported producing pressures of up to 1.5 atmospheres at the acetabular surface and sustaining them for up to 2 minutes, but made no mention of the insertion force used. Oh, Merckx and Harris (1983) have used localised high pressure produced by using a special adaptor and inserting a cement gun into drill holes as well as more general, lower, pressures provided by a special device. Both these methods provide an improved depth of cement intrusion when compared with finger packing.

Cement is a visco-elastic material, and the degree of viscosity and elasticity and their relationship varied enormously during polymerisation. Oh et al. (1983) commented that, because of this visco-elasticity, instantaneous high pressure cannot provide deep penetration over the entire acetabulum, and that a sustained lower pressure is more effective in causing intrusion of cement into the small cancellous pores. The same paper continues "with most cup designs adequate intrusion of cement cannot be achieved due to free escape of cement along the periphery of the cup". Pressurisation of cement has been shown by Markolf et al. (1984) to be effective in causing cement to flow into small pores. A slight increase in pressure gave important benefits in flow rates and in cancellous bone penetration.

Just as inadequate cement intrusion may give rise to poor socket fixation, excessive penetration may be equally detrimental by causing bone death deep within the cement and extensive loss of bone should the socket require revision. Krause, Krug and Miller (1982) failed to find a statistical correlation between depth of intrusion and strength of fixation. In several cases they found that 2 or $3 \mathrm{~mm}$ of penetration resulted in a similar tensile strength between bone and cement to that produced by $10 \mathrm{~mm}$ penetration. Huiskes and Sloof (1981) reported that $10 \mathrm{~mm}$ of penetration is likely to give rise to thermal damage to bone.

Oh, Sanders and Treharne (1985) have shown, in vitro, that a socket with an accurately fitting flange can generate high pressures and consequently greatly improve cement intrusion into cancellous bone. However, in this study they used very large forces when inserting the flanged cups; these were as much as 2912 Newtons, probably ten times the force a surgeon would be capable of sustaining for the whole period of polymerisation.

Conclusions. Our study supports the evidence that a small back-pressure of blood, of the order of $25 \mathrm{mmHg}$, has an effect which, if unopposed, will be highly detrimental to socket fixation. The ineffectiveness of an unflanged socket in allowing adequate injection into cancellous bone and the maintenance of that intrusion has been demonstrated. Another effect of this design is that such sockets are difficult to implant concentrically within the acetabulum without bottoming out. This may leave a situation in which load-bearing polyethylene is in contact with bone in the presence of imperfect fixation (Wroblewski et al. 1987).

It is apparent that there are considerable differences in the intrusion properties of the two cements which we tested. Palacos with gentamicin intruded more than CMW Type 1, but consequently showed an equally greater liability to be extruded. If, however, the cement continues to be contained and pressurised, then extrusion does not occur.

Surgical technique must take into account the properties of bone cement. Methylmethacrylate cement is visco-elastic and if its injection into bone is to be optimised, it is important that it is placed under a pressure greater than the bleeding pressure within bone, and that this pressure is maintained until polymerisation is complete. A modest insertion force of $8 \mathrm{~kg}$ has been demonstrated to be adequate in producing a pressure of at least $170 \mathrm{mmHg}$ under an ogee-flanged socket, and this pressure can be maintained for the duration of polymerisation. Should the insertion force cease at any time before polymerisation is complete, then it must be expected that a proportion of the intruded cement will be expelled. Thus the advantage of the Exeter pressuriser may readily be lost if it is used in conjunction with an unflanged socket.

It is important that the flanged socket is used with due regard to its design. If the flange is not trimmed enough then its rim may come against bone, "rim out", 
and prevent full pressurisation. If it is trimmed too much the body of the socket may bottom out and prevent further pressurisation. The ogee flange is asymmetrical; the problems of trimming can readily be avoided if the inferior, anterior and superior parts of the flange are cut to fit just inside the acetabular rim, whilst the posterior part of the flange is left relatively large to fit on to the acetabular rim. The posterior part is more flexible than the other areas of the flange and will bend under modest force to facilitate pressurisation. Our experimental results support the concept that the Charnley ogeeflanged socket can improve cement injection.

This article was accepted before a conflict of interest policy had been introduced

\section{REFERENCES}

Huiskes R, Slooff TJ. Thermal injury of cancellous bone, following pressurized penetration of acrylic cement. Trans Orthop Res Soc $1981 ; 6: 134$

Krause WR, Krug W, Eng B, Miller J. Strength of the cement-bone interface. Clin Orthop 1982;163:290-9.
Lee AJ, Ling RS. A device to improve the extrusion of bone cement into the bone of the acetabulum in replacement of the hip joint. Biomed Eng 1974;9:522-4.

Lee AJC. What do we expect from the prosthesis-bone-cement interface? Revision Arthroplasty 2. Proceedings of a symposium held in Harrogate March 1983. 1983;8-13.

Markolf KL, Kabo JM, Stoller DW, Zager SA, Amstutz HC. Flow characteristics of acrylic bone cements. Clin Orthop 1984;183:246-54.

Oh I, Merckx DB, Harris WH. Acetabular cement compactor: an experimental study of pressurization of cement in the acetabulum in total hip arthroplasty. Clin Orthop 1983;177:289-93.

Oh I, Sanders TW, Trehame RW. Total hip acetabular cup flange design and its effect on cement fixation. Clin Orthop 1985;195:304-9.

Wroblewski BM. Charnley low friction arthroplasty in patients under the age of $\mathbf{4 0}$ years. In : Sevastik J, Goldie I, eds. The young patient with degenerative hip disease. Stockholm: Almqvist \& Wiksell, 1985:197-201.

Wroblewski BM. Direction and rate of socket wear in Charnley lowfriction arthroplasty. J Bone Joint Surg [Br] 1985;67-B:757-61.

Wroblewski BM. 15-21-year results of the Charnley low-friction arthroplasty. Clin Orthop 1986;211:30-5.

Wroblewski BM, Lynch M, Atkinson JR, Dowson D, Isaac GH. External wear of polyethylene socket in cemented total hip arthroplasty. J Bone Joint Surg [Br] 1987;69-B:61-3. 